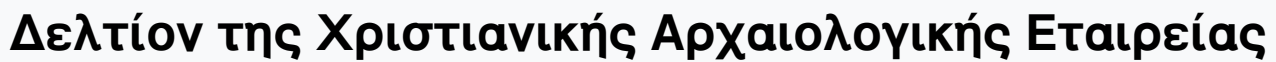

Tó 20 (1999)

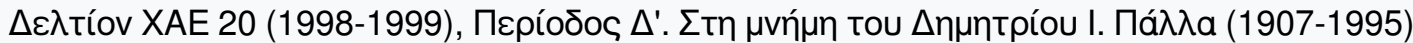

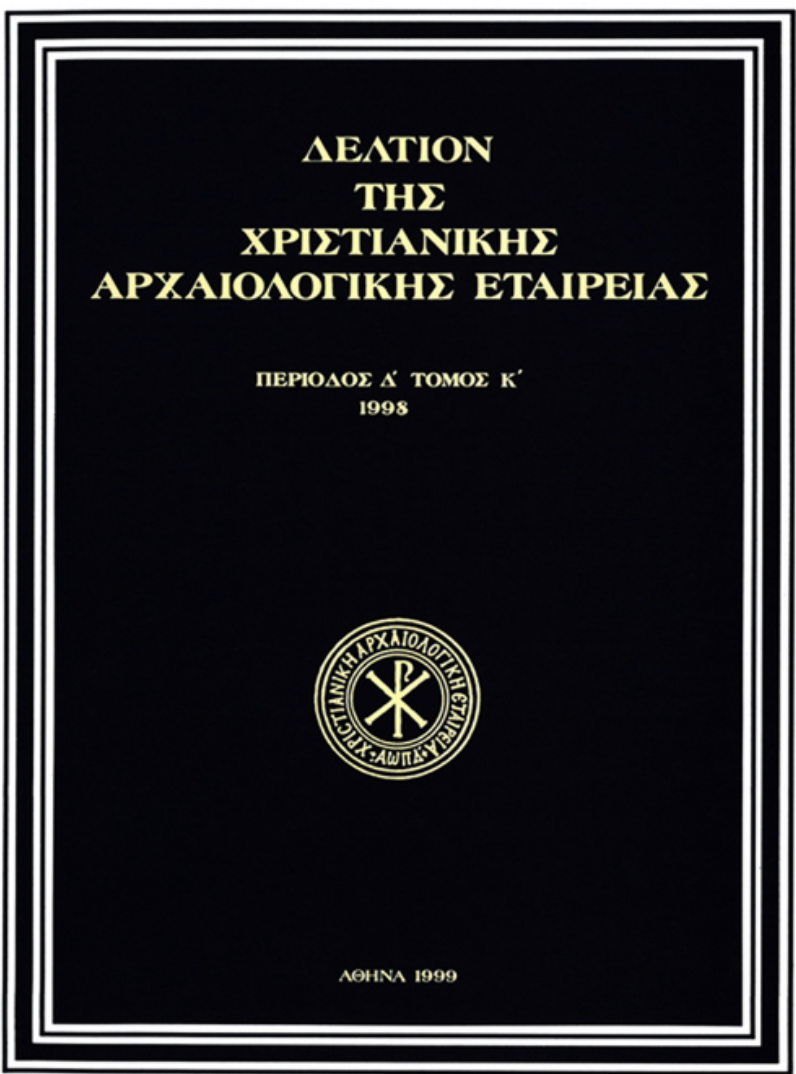

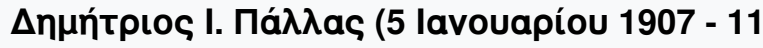

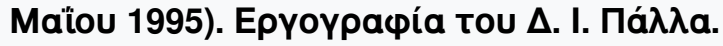

'Oגya ГKPATZIOY

doi: $\underline{10.12681 / \text { dchae. } 1185}$

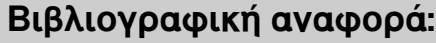

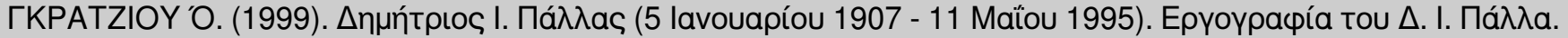

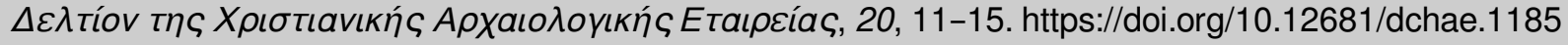




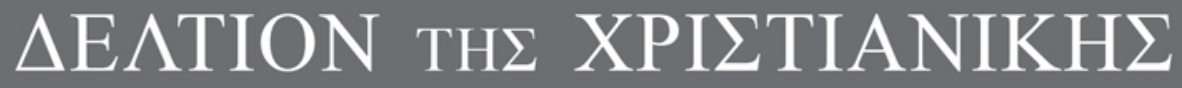 APXAIO $\Lambda$ OГIKH $\Sigma$ ETAIPEIA $\Sigma$}

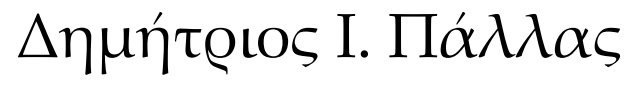

'O $\gamma \gamma \alpha$ ГKPATZIO

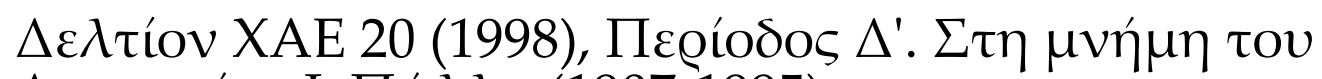
$\Delta \eta \mu \eta \tau \varrho i ́ o v ~ I . ~ \Pi \alpha ́ \alpha \lambda \lambda \alpha$ (1907-1995)

A@HNA 1999

EONIKO KENTPO 


\section{$\triangle \mathrm{HMHTPIO} \Sigma$ I. ПА $\Lambda$ А $\Sigma$}

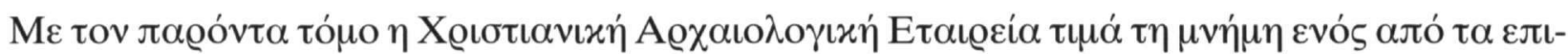

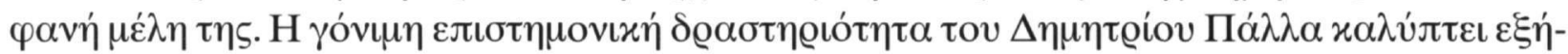

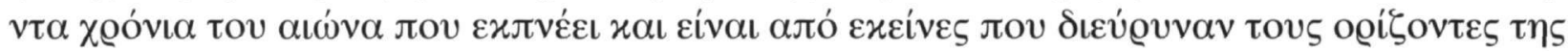

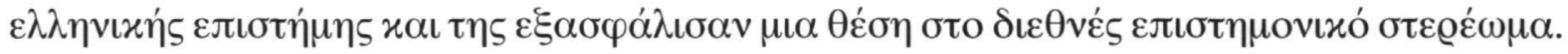

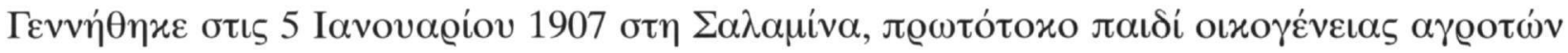

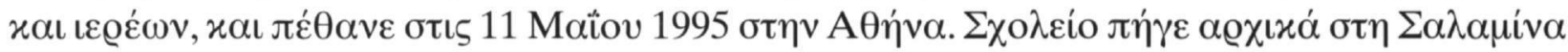

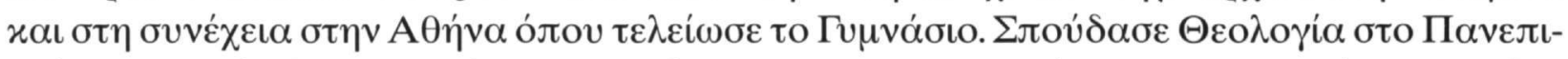

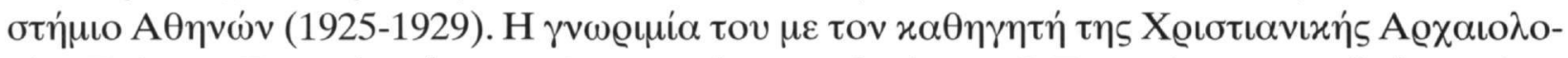

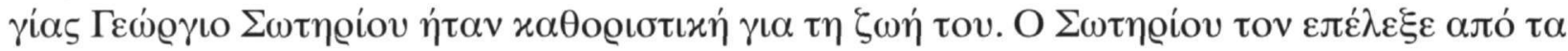

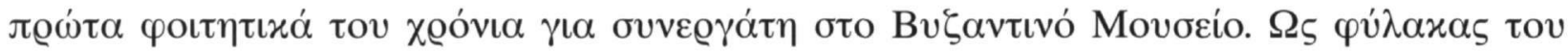

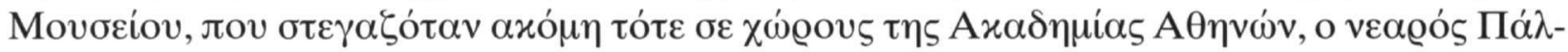

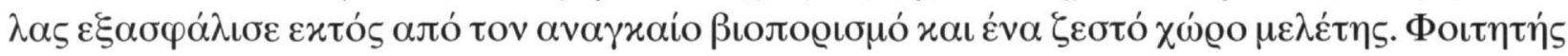

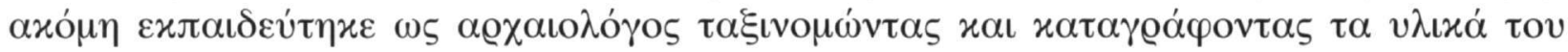

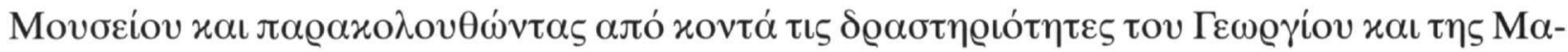

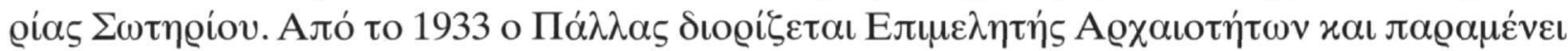

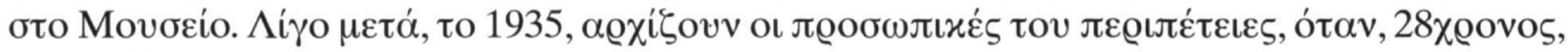

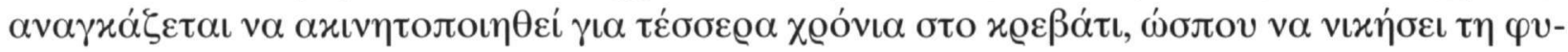

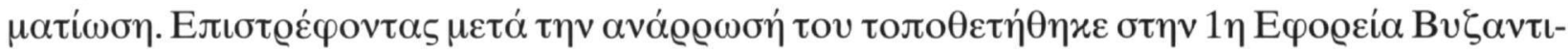

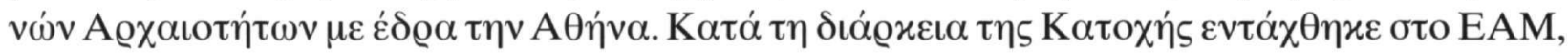

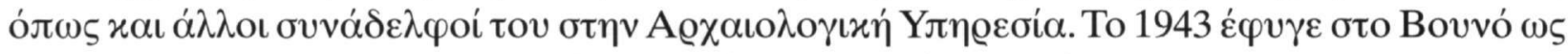

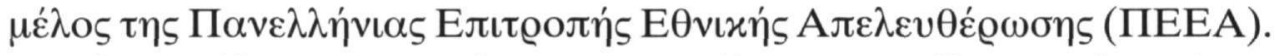

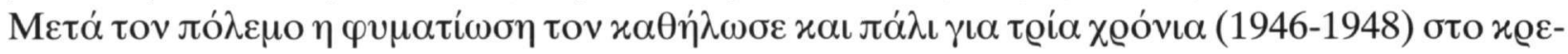

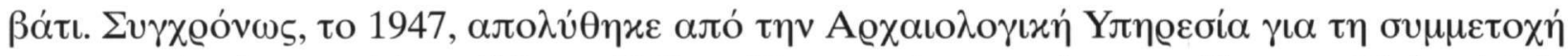

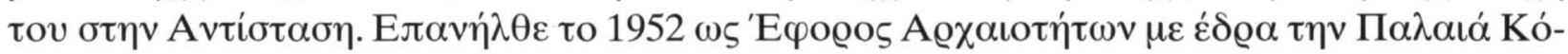

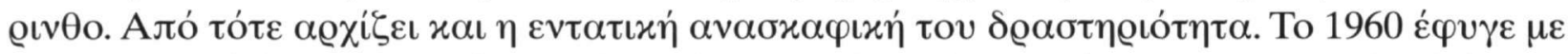

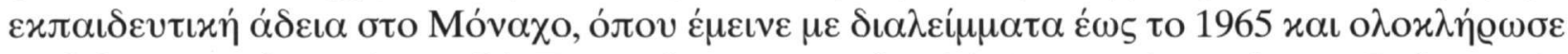

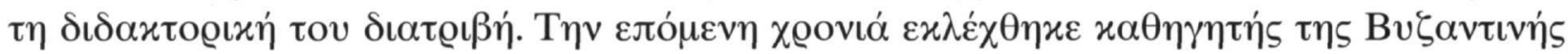

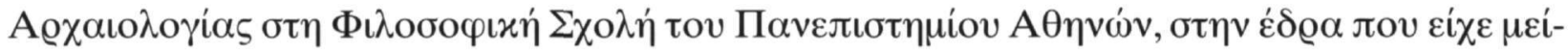

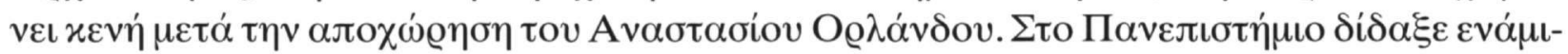

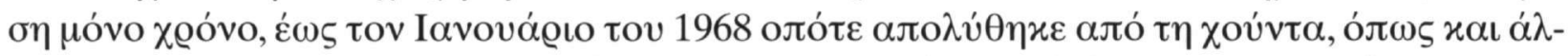

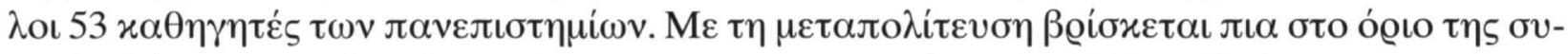

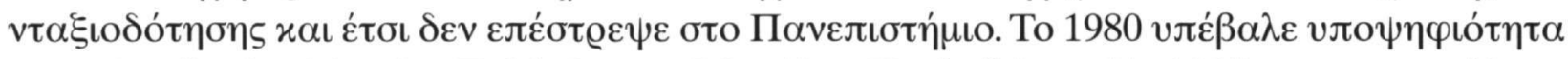

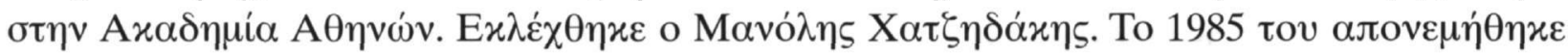

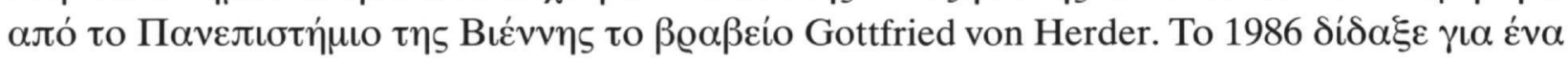

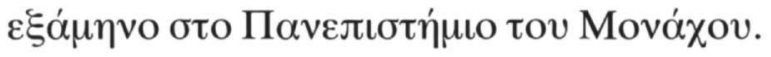




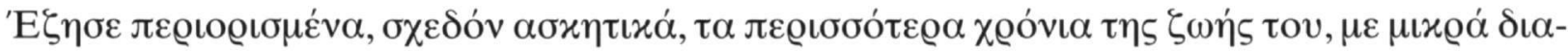

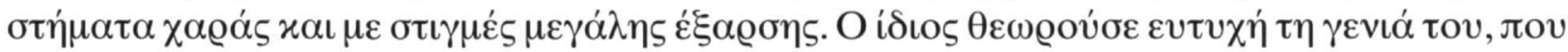

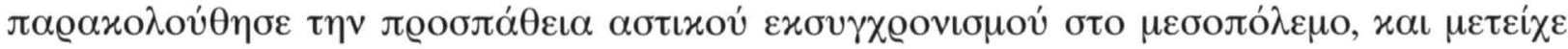

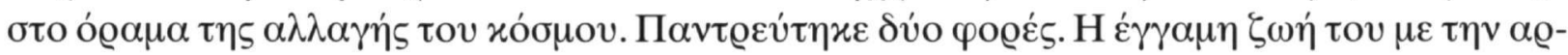

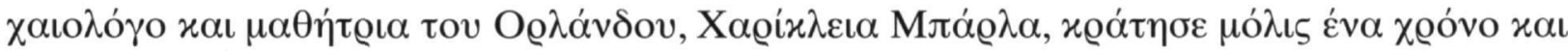

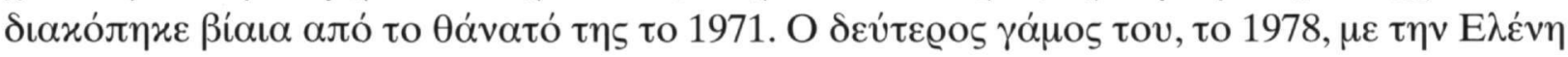

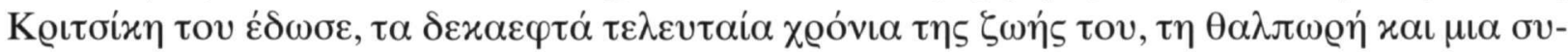

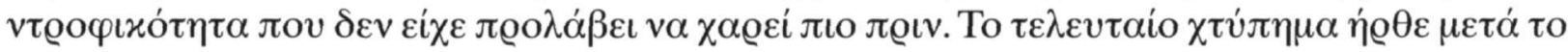

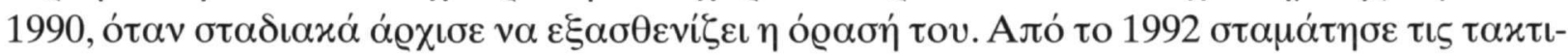

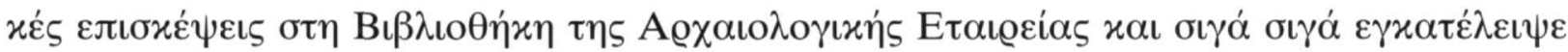

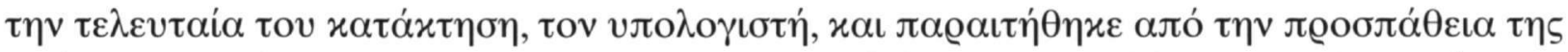

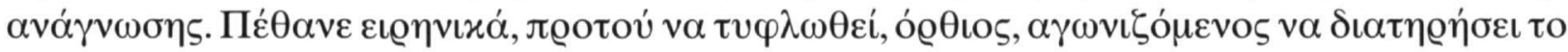

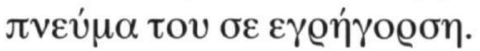

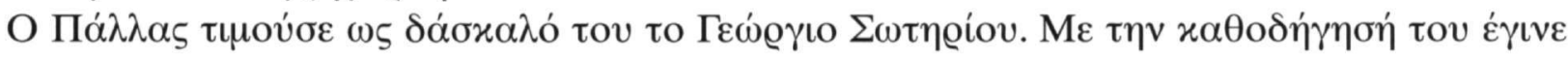

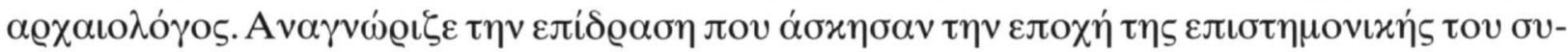

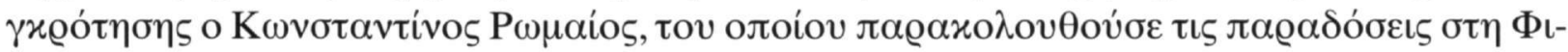

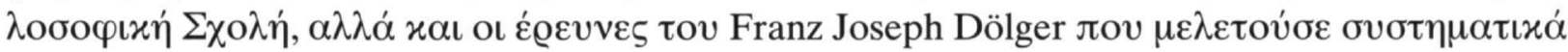

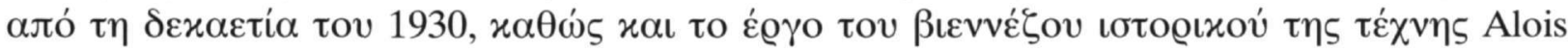

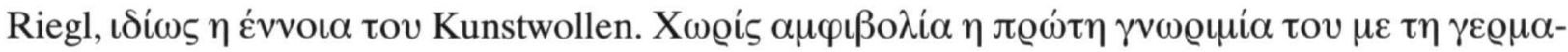

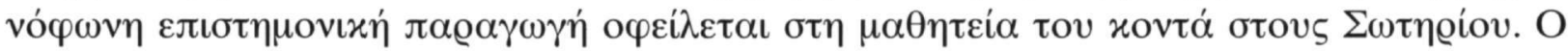

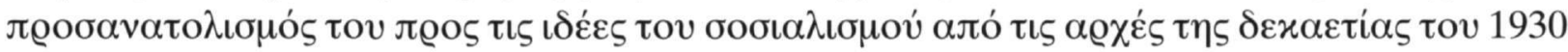

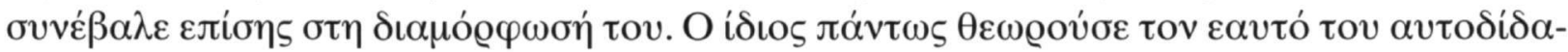

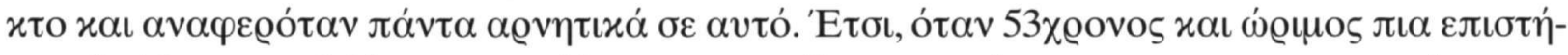

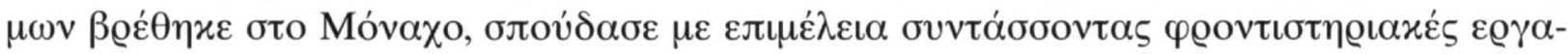

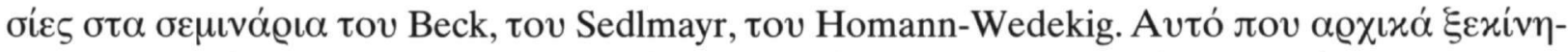

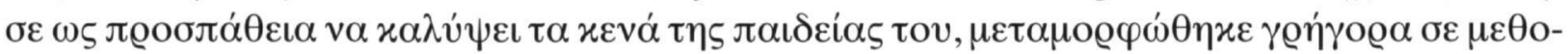

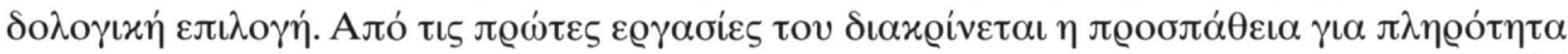

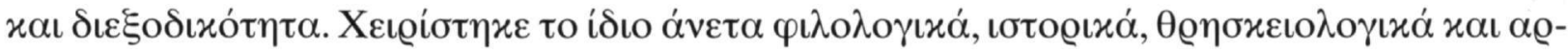

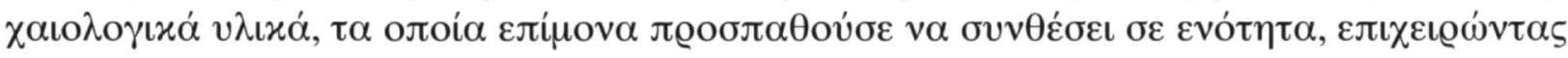

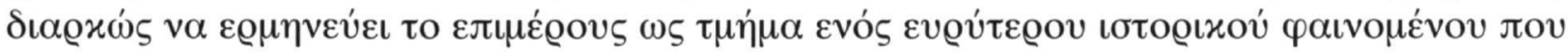

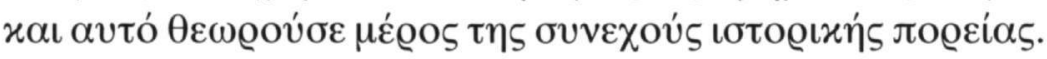

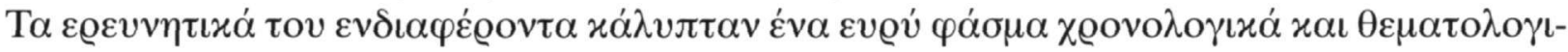

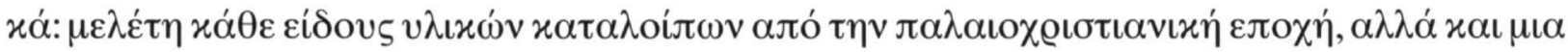

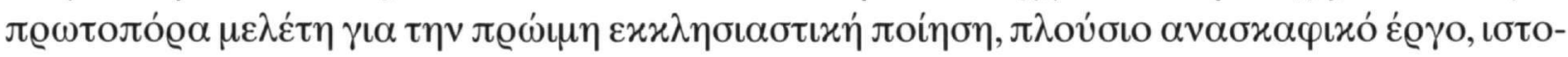

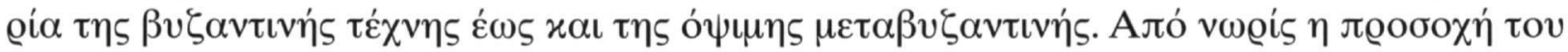

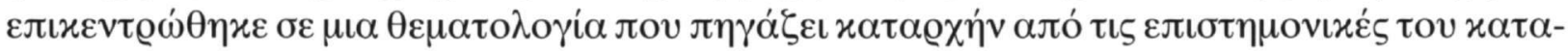

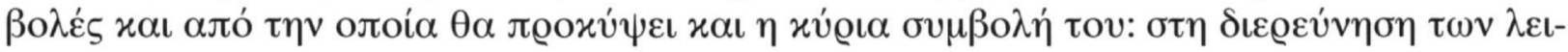

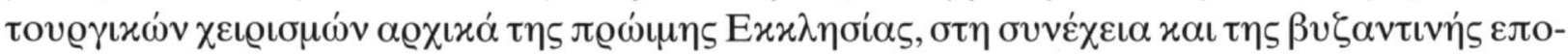

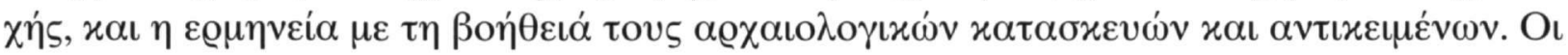

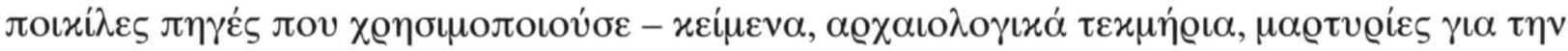

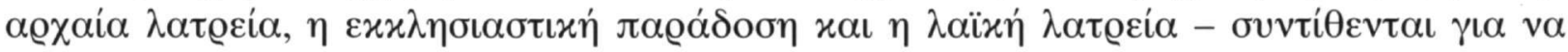

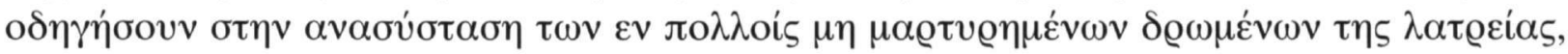




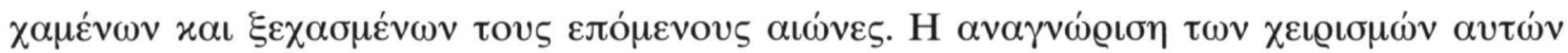

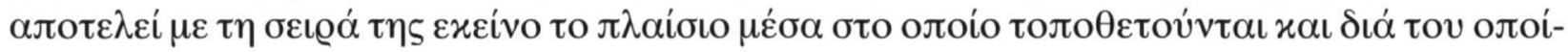

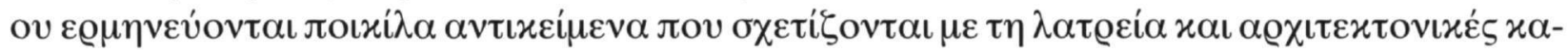

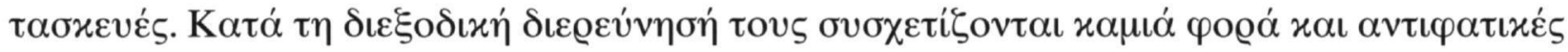

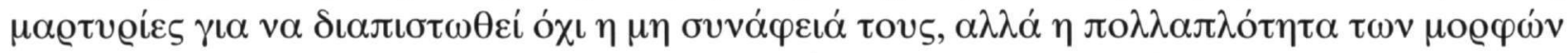

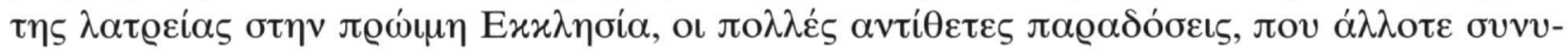

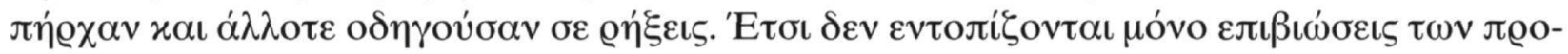

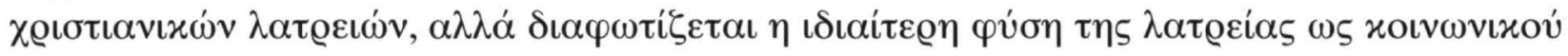

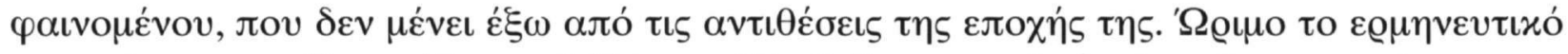

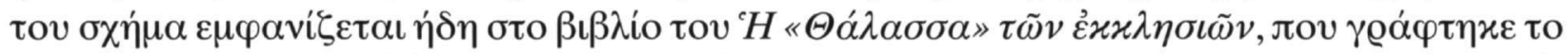

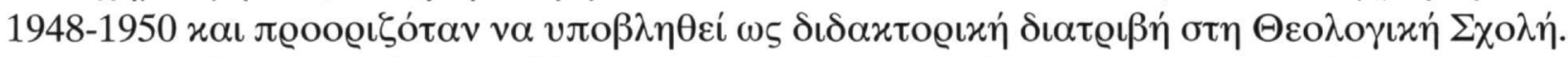

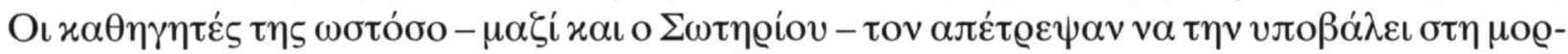

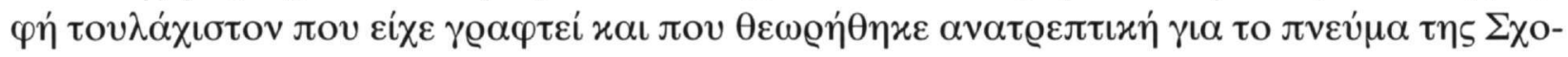

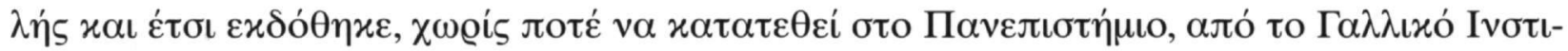

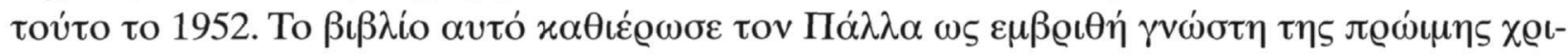

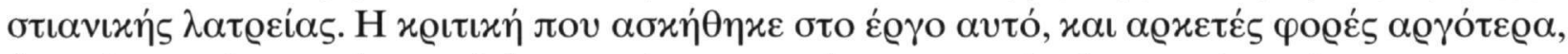

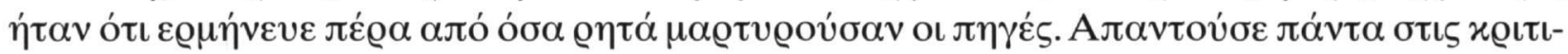

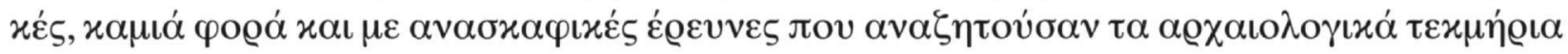

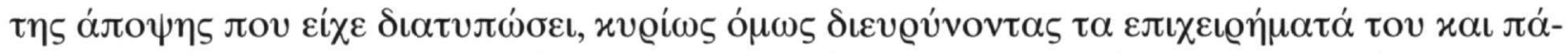

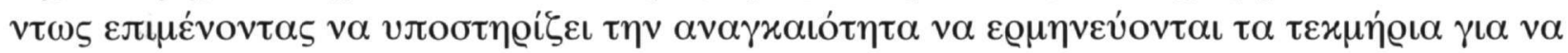

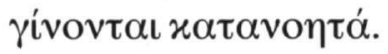

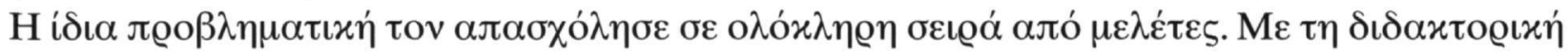

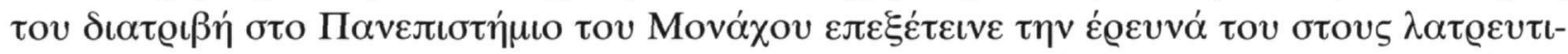

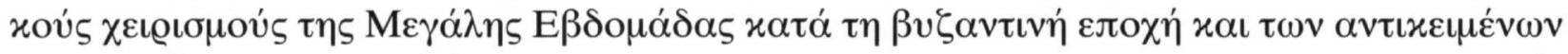

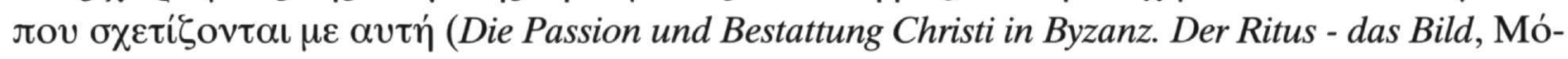

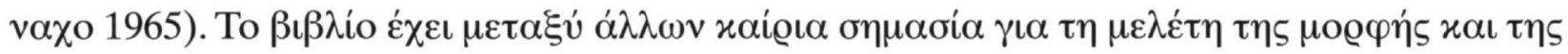

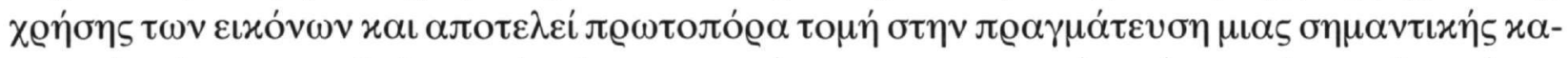

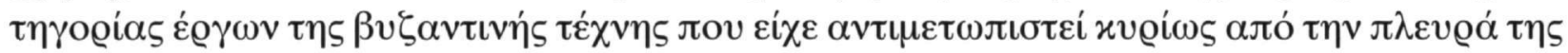

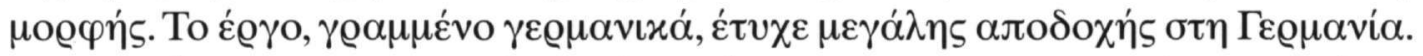

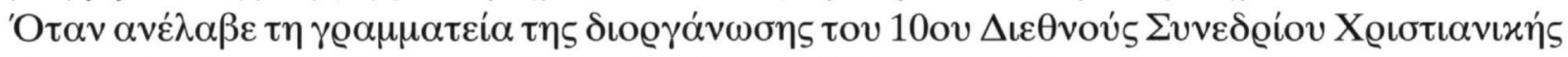

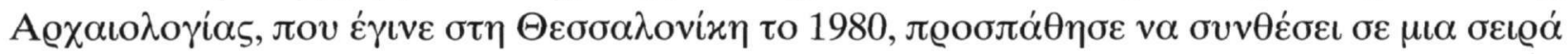

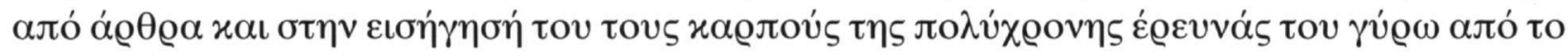

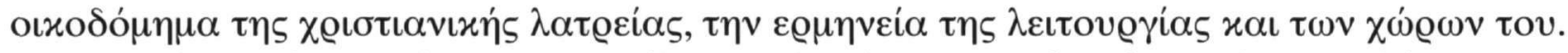

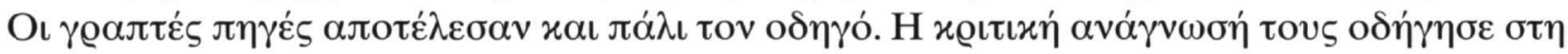

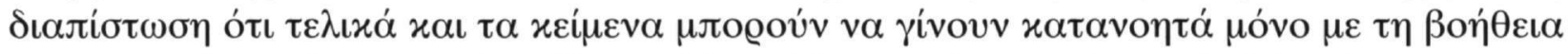

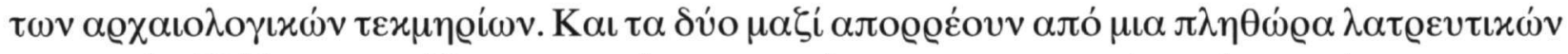

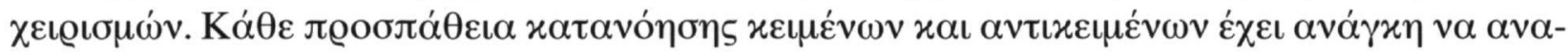

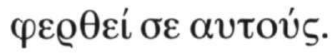

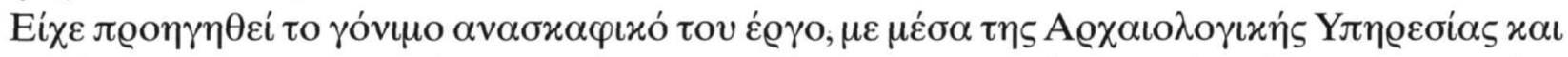

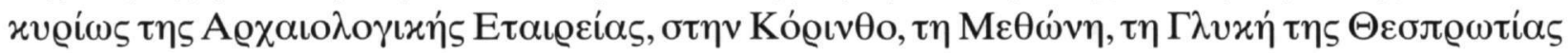

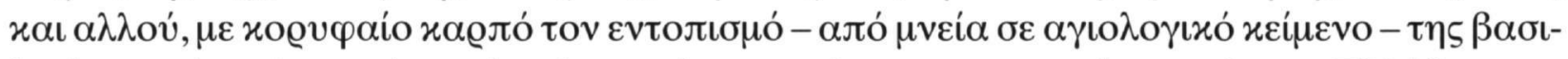

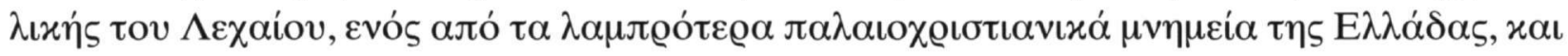




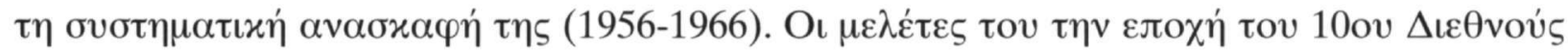

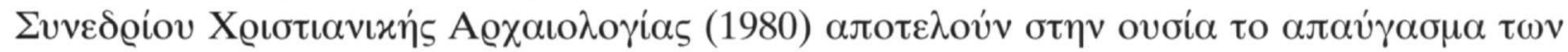

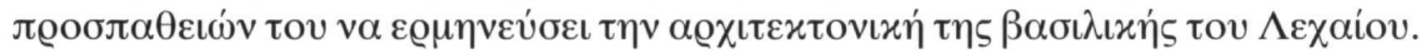

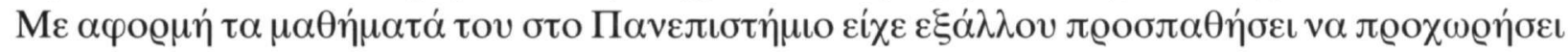

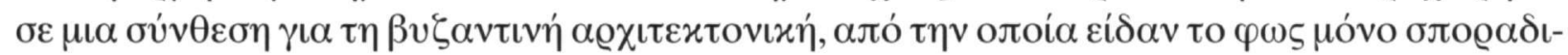

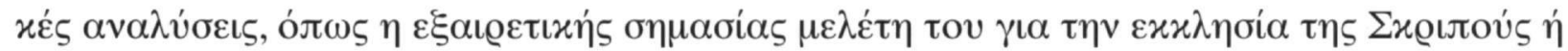

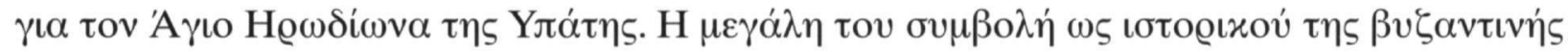

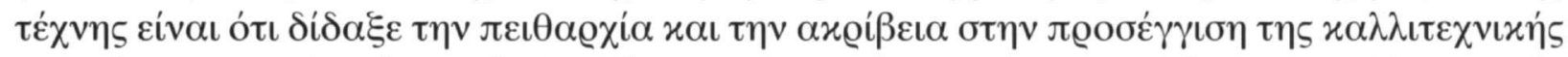


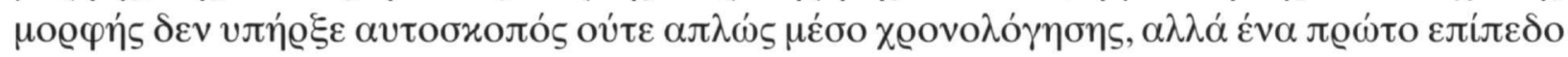

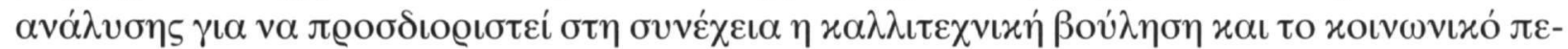

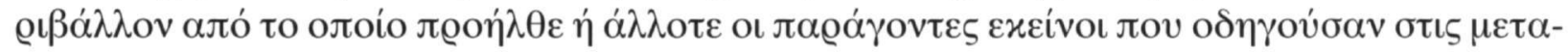

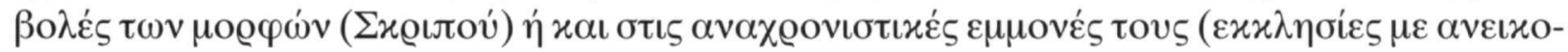

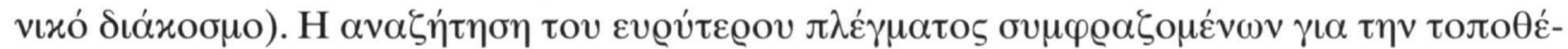

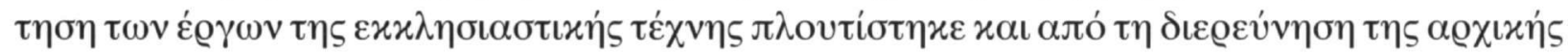

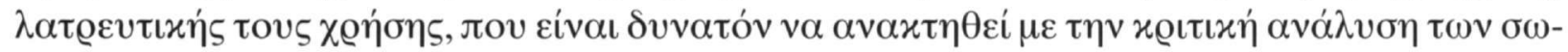

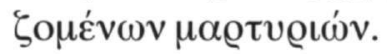

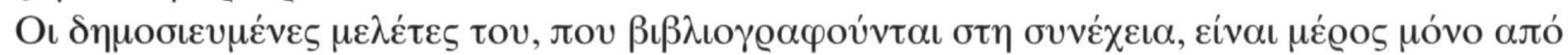

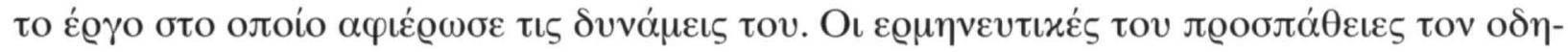

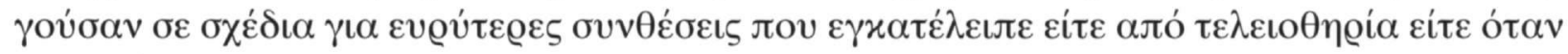

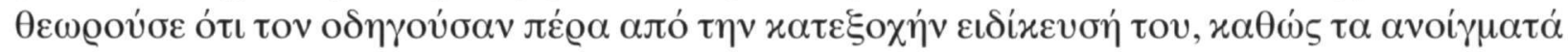

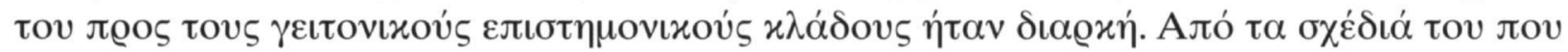

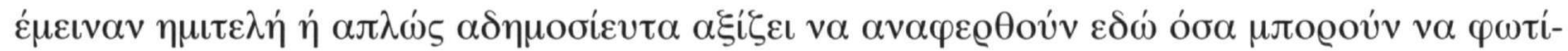

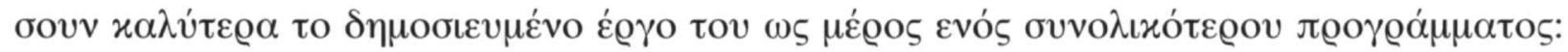

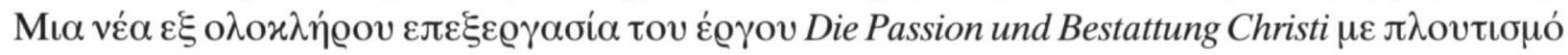

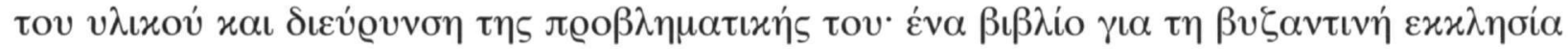

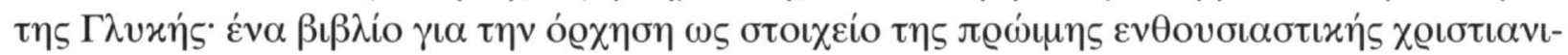

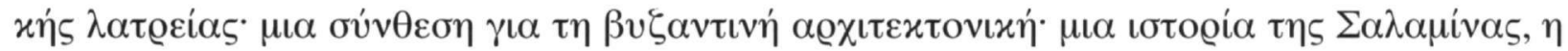

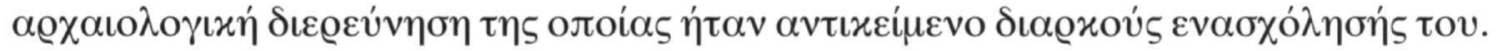

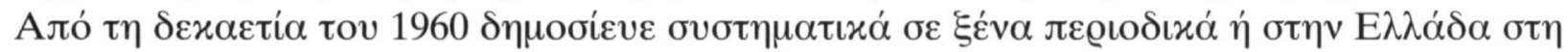

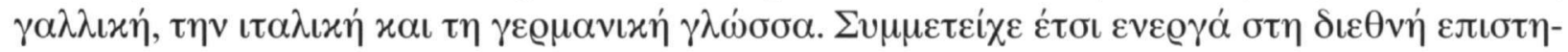

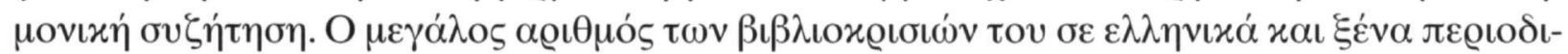

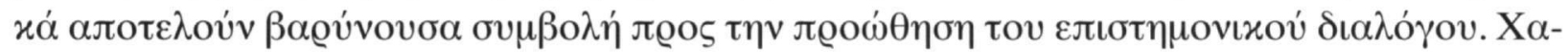

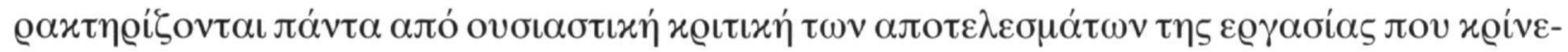

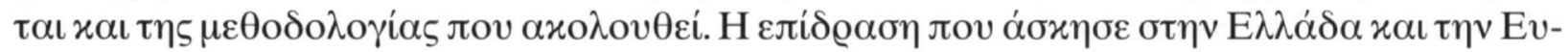

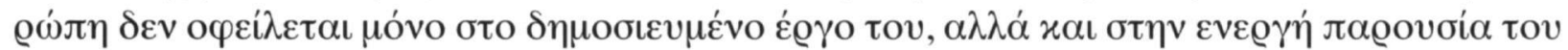

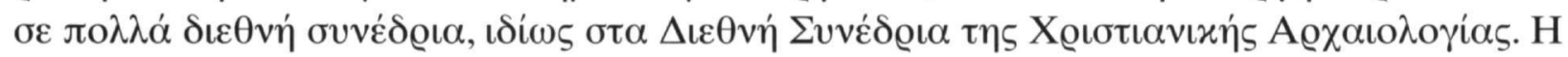

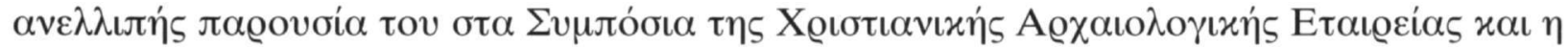

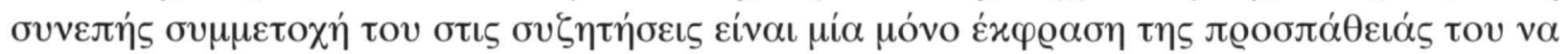

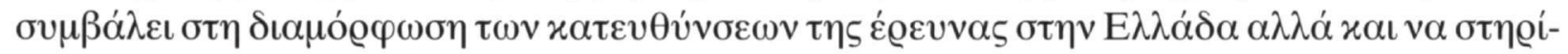

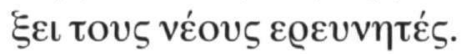

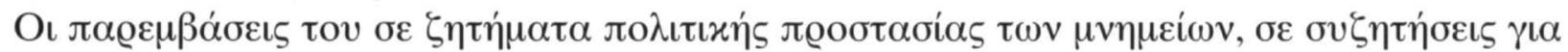




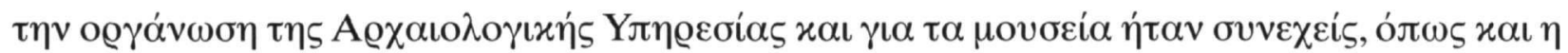

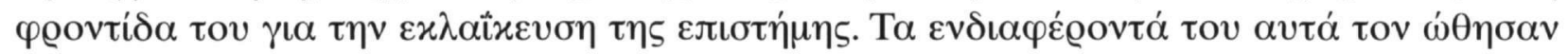

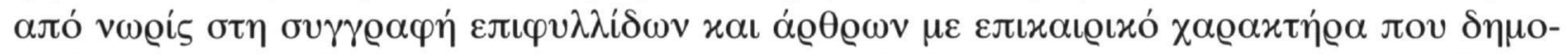

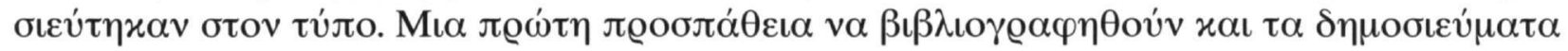

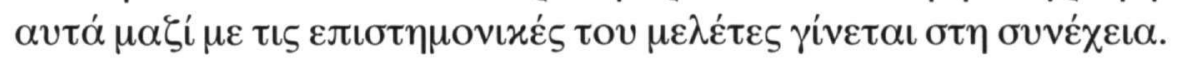

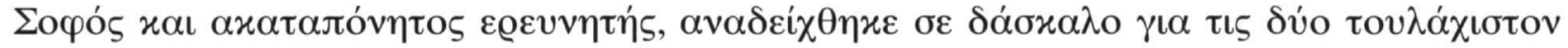

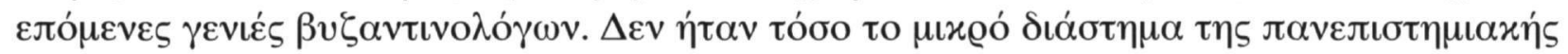

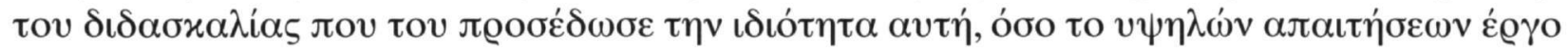

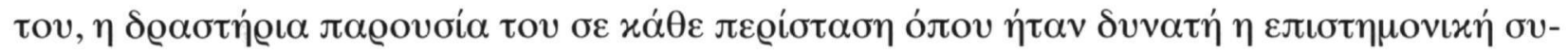

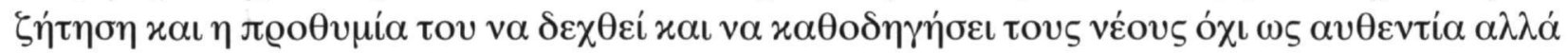

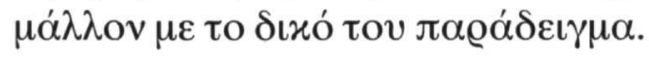

ОАГА ГКРАТZIOY

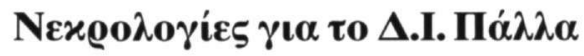

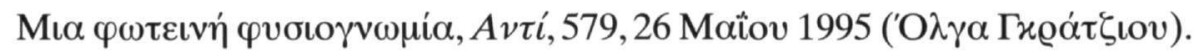

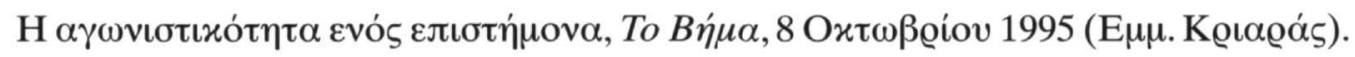

$\Delta \eta \mu \eta \dot{\imath \varrho \iota ૬ ~ \Pi \alpha ́ \lambda \lambda \alpha \varsigma ~(1907-1995), ~ П \alpha \varrho v \alpha \sigma \sigma o ́ \varsigma ~ \Lambda Z ' ~(1995), ~ \sigma . ~ 482-485 ~(N ı x o ́ \lambda \alpha o \varsigma ~ \Lambda \alpha ́ \sigma x \alpha \varrho \eta ऽ) . ~}$

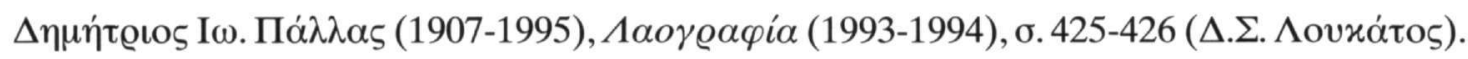

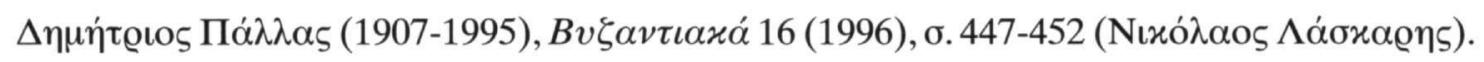

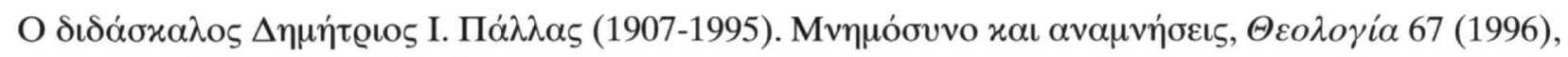

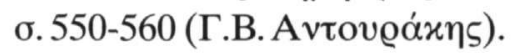

Double hommage à Demétrios I. Pallas (1906-1995), Antiquité Tardive 5 (1997), б. 8-10 (Georges Kiourtzian, Noël Duval).

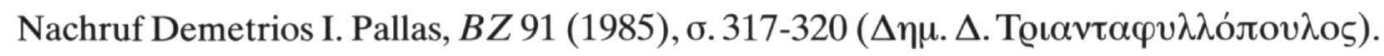

